\title{
"UN PARQUE EXTENSO Y AMPLIO PARA DOTAR CON ÉL A NUESTRA QUERIDA CAPITAL": LA EXIGENCIA DE LA CREACIÓN DE UN PARQUE Y EL PANORAMA DEL ARTE PAISAJÍSTICO A FINALES DEL SIGLO XIX EN BOGOTÁ
}

\author{
"A WIDE AND SPACIOUS PARK FOR OUR BELOVED CAPITAL": \\ THE DEMAND OF THE CREATION OF A PARK AND THE GARDEN ART \\ AT THE END OF THE $19^{\text {TH }}$ CENTURY IN BOGOTÁ
}

\begin{abstract}
Claudia Cendales Paredes
PhD en Historia del Arte. Tema: "Los parques públicos de Bogotá: su aparición, significado y desarrollo 1886-1938", TU Berlín. Tiene master of science en Restauración de Monumentos Arquitectónicos, TU Berlín y magíster artium en Historia del Arte - Etnología y Sociología, Ludwig-Maximilians-Universität Munich. Actualmente trabaja en MWA, Büro für Denkmalpflege, Berlín con proyectos de restauración de monumentos arquitectónicos.

claudiacendales@googlemail.com
\end{abstract}

\section{RESUMEN}

Este artículo trata sobre la aparición, desarrollo y significado de los parques públicos de Bogotá a finales del siglo XIX, que resultaron de la conversión de las antiguas plazas coloniales. De igual manera demostrará que paralelamente a este fenómeno existía un amplio panorama del arte de la jardinería en Bogotá, que incluía la exigencia de creación de parques acordes a las necesidades reales de la ciudad.

Palabras clave: Parques y jardines públicos, diseño y función de parques y jardines públicos, historia del paisajismo suramericano, paisajistas suramericanos, Bogotá - Colombia.

\begin{abstract}
The theme of the article is the origin and significance of public parks in Bogotá at the end of the 19th, which appeared after the reformation of the old colonial squares. The aim of the article is also to demonstrate, that at the same time of the formation of the first described parks of Bogotá, there was a discussion about creating new parks, which contribute to improve the real situation of the city.
\end{abstract}

Keywords: Public gardens and parks/design and function of public gardens and parks/south american garden history/south american landscapers/Bogotá-Colombia

En el año de 1901 aparece consignado en un acta del Ministerio de Fomento, encargado de la administración de los parques y los jardines públicos de Bogotá la necesidad de "(...) la construcción de un parque extenso y amplio para dotar con el a nuestra querida capital (...) Todos estamos sintiendo las consecuencias dolorosas del notabilísimo desaseo en que se encuentran nuestras plazas, calles, (...) ríos (...) el azote ha sido tan general que no hay un habitante de la ciudad que no implore el aseo como único medio de conservar su salud y su vida"l. Esta afirmación demuestra que, poco después de la aparición de los primeros parques públicos en Bogotá resultados de la conversión de antiguas plazas coloniales a finales del siglo XIX, se exigía la creación de otro tipo de parques, que estuvieran acordes a la situación real de la ciudad. Este 
artículo tratará en primera instancia la aparición, diseño y principales elementos de los primeros parques y jardines públicos, provenientes de plazas coloniales. De igual manera intentará describir el panorama del arte de la jardinería a finales del siglo XIX en Bogotá.

Por un lado Bogotá era retratada durante el siglo XIX como una ciudad con una situación geográfica muy peculiar, como lo afirmaría Alexander von Humboldt en su diario durante su visita en 1801 "Ciudad máximo 30000 habitantes - yace en el pie de una cordillera, mientras que se hubiera podido buscar en toda la meseta un lugar mejor (...) Es una empresa singular asentarse en la (...) cima de una montaña de una altura, que sobrepasa la espalda de los Pirineos". ${ }^{2}$ Y es que desde su fundación en 1538 Bogotá había sido marcada por tres elementos topográficos, que influyeron su forma y fisonomía y que fueron vistos por mucho tiempo como parte de ella: los Cerros Orientales, una formación montañosa perteneciente a la Cordillera de los Andes al oriente, la Sabana de Bogotá y los numerosos ríos, que atravesaban la ciudad. ${ }^{3}$ Como muchas otras ciudades latinoamericanas Bogotá fue construida con base en un trazado de damero, cuyo punto de partida era una plaza central, la Plaza Mayor, alrededor de la cual se distribuyó el territorio en grandes bloques. La Plaza Mayor era el punto de orientación más importante y representaba no solamente en sentido urbanístico, sino también en sentido simbólico el centro de la ciudad ${ }^{4}$ (Figura 1). Por otro lado, la ciudad era descrita durante el siglo XIX por numerosos viajeros como una pequeña aldea. Sin embargo, y a pesar que Bogotá no alcanzaba la extensión y la población de otras ciudades latinoamericanas, si padecía lamentables condiciones higiénicas. Esta situación resultaba por la alta densidad, y por el precario abastecimiento de servicios públicos. ${ }^{5}$ Por estas condiciones higiénicas se empezó a deteriorar la ya descrita estrecha relación de la ciudad con sus alrededores.

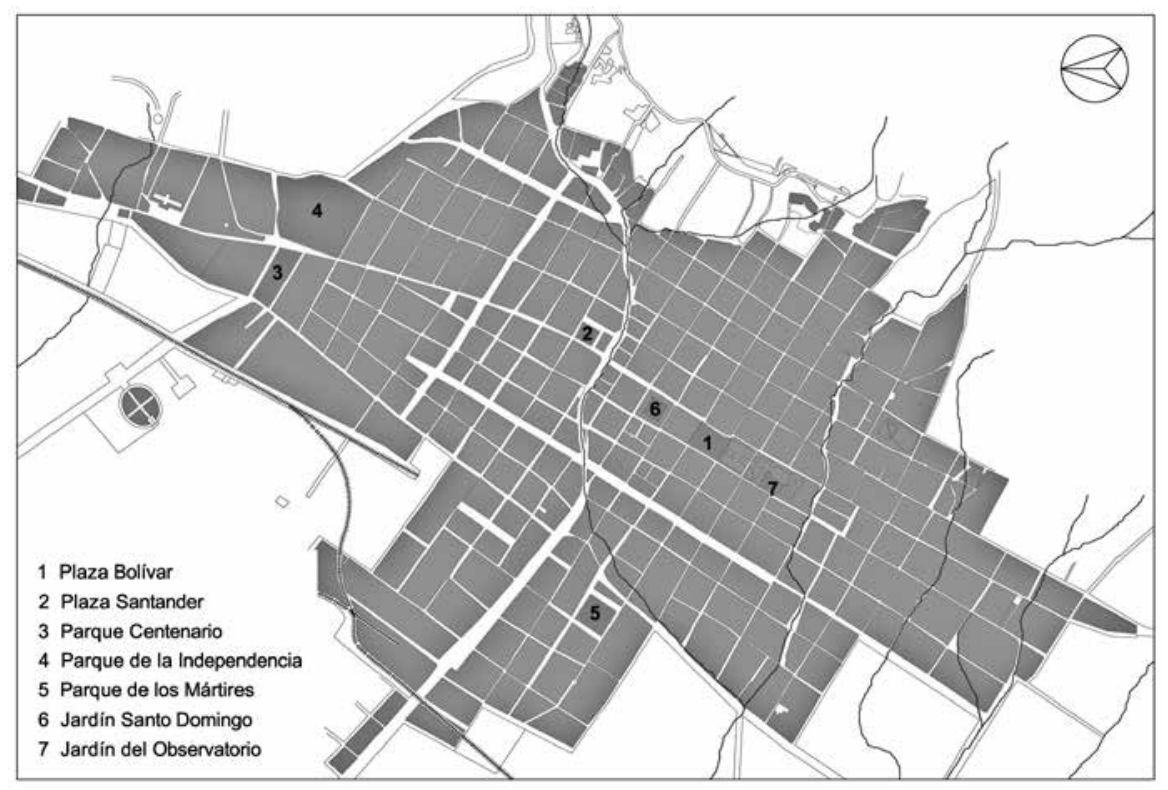

Figura 1: Localización Plaza Mayor o Plaza de Bolívar Fuente: Plano de Bogotá. Dibujo CAD 
Por último, después de la Independencia de Colombia en 1810, la búsqueda de una identidad propia había sido un tema importante, que se vio traducido en algunos cambios en el espacio público de la ciudad. Entre estos cambios estaban la modificación de la nomenclatura, que databa de la época colonial en 1849, por nombres de sitios, relacionados con las Guerras de Independencia o según provincias latinoamericanas, ${ }^{6}$ así como el levantamiento de monumentos dedicados a los héroes de las Guerras de Independencia. El primero de estos monumentos fue erigido en la Plaza Mayor en 1846 en honor a Simón Bolívar (1783-1830) y realizado por el escultor italiano Pietro Tenerani (1789-1869). La Plaza Mayor recibió el nombre de Plaza de Bolívar (Figura 2). En febrero de 1880 se decidió por iniciativa del Ministerio de Educación encargar al jardinero Casiano Salcedo (?-1918) con la construcción de un parque o jardín en la Plaza de Bolívar. ${ }^{8}$ La Plaza de Bolívar sería la primera de las plazas coloniales que fueron convertidas en parque o jardín público en Bogotá. 9 El parque de la Plaza de Bolívar fue realizado sobre un área cuadrada localizada en la mitad de la plaza (Figuras 3 y 4). El
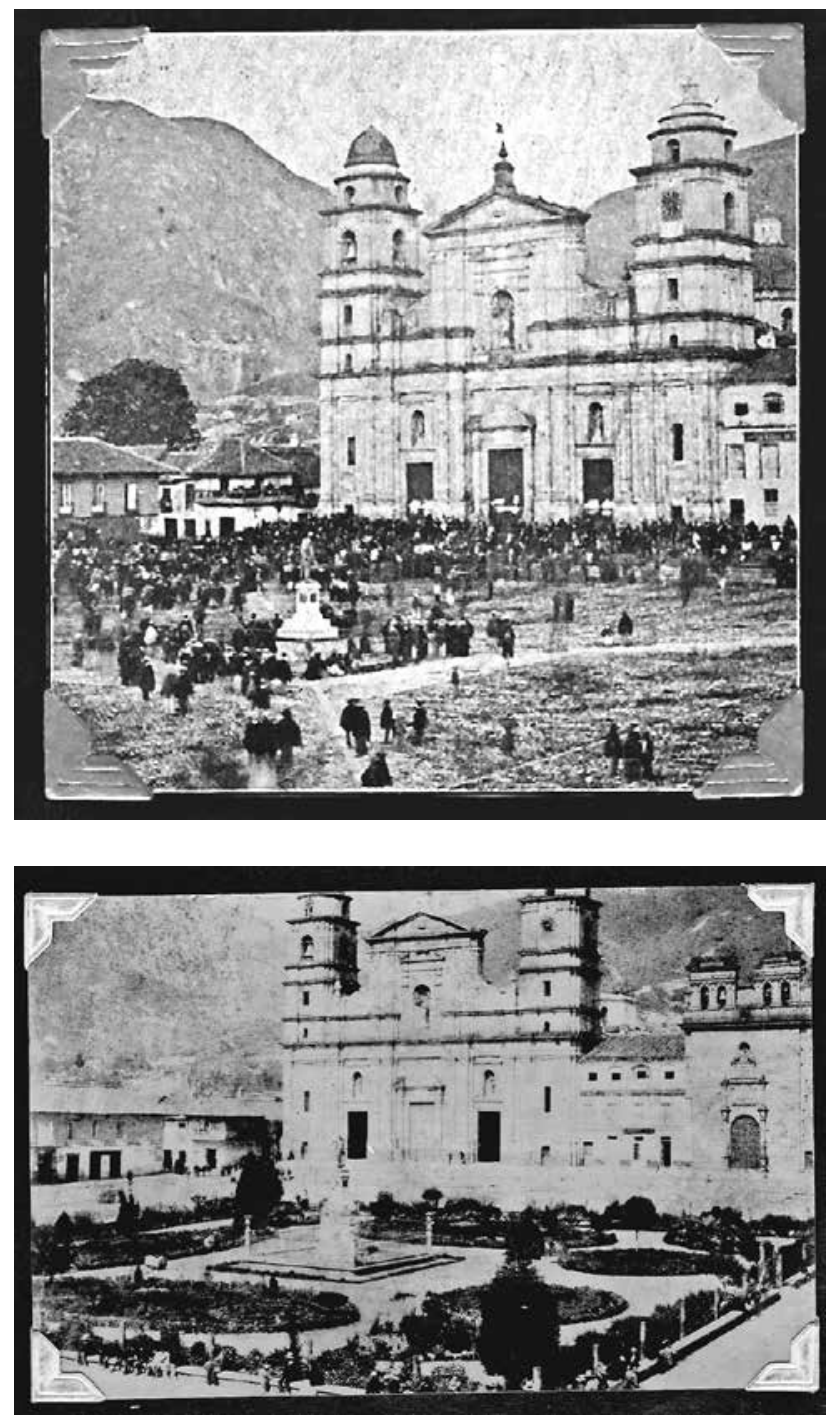

Figura 2: Plaza de Bolívar con Monumento a Simón Bolívar, vista hacia el oriente

Fuente: Archivo Sociedad de Mejoras y Ornato de Bogotá a continuación: SMOB, Archivo José Vicente Ortega Ricaurte (a continuación Archivo JVOR), n. registro VIII-613a
Figura 3: Plaza de Bolívar, vista hacia el oriente después de la jardinización Fuente: SMOB, Archivo JVOR, n. registro $X V-1234 c$ 


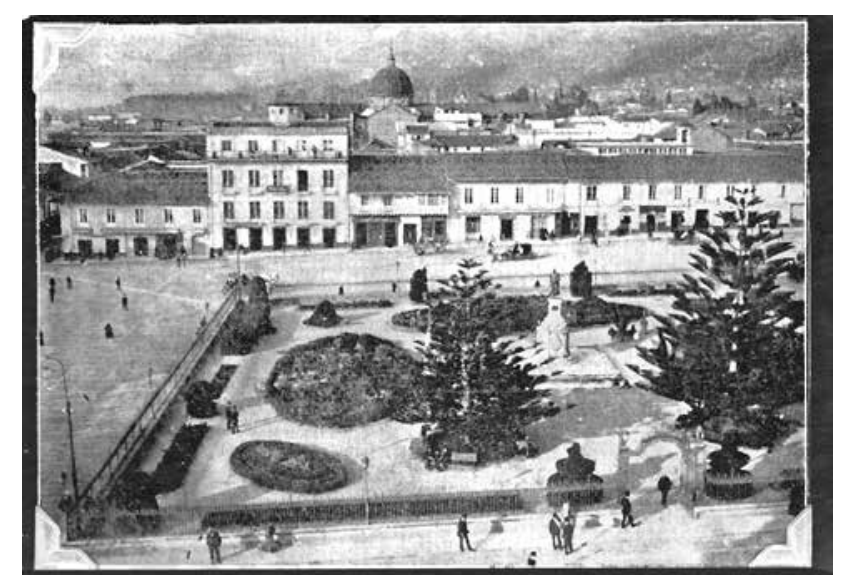

Figura 4: Plaza de Bolívar, vista hacia el norte después de la jardinización Fuente: SMOB, Archivo $J V O R$, n. registro $X V I-1264 c$

diseño del parque se caracterizaba por su simetría. En su mitad se encontraba, rodeado por una reja baja, el monumento a Bolívar, que constituía tanto en sentido estético, como simbólico el centro del parque. Paralelamente a esta reja se formó a cada uno de los lados norte, occidente y oriente un cuadro de forma oval. En la parte sur, en la que se encontraba la puerta de entrada del parque, se construyeron en vez de un gran cuadro oval, dos redondos de menor tamaño. Sobre cada uno de ellos se sembró en 1892 una araucaria excelsa. ${ }^{10}$ En las esquinas del parque fueron hechos cuadros ovalados más pequeños, que lo enmarcaban y repetían el motivo del lado sur. Paralelo a la reja exterior del parque se encontraban cuadros rectos, interrumpidos por árboles solitarios.

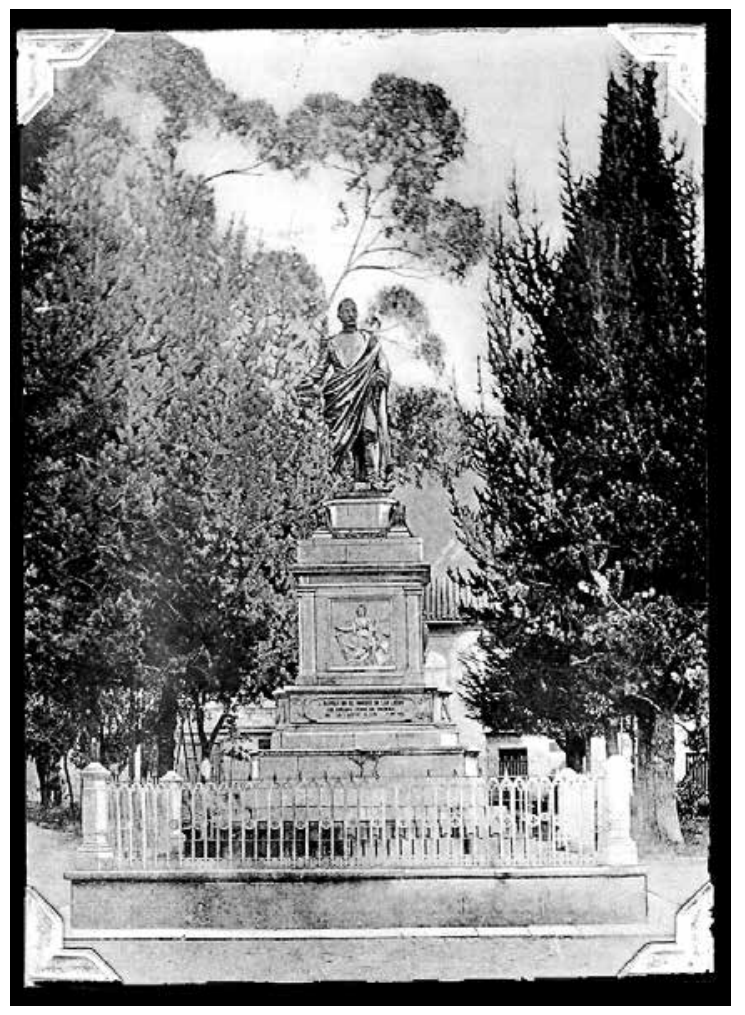

Figura 5: Plaza

Santander, estatua de

Santander

Fuente: SMOB, Archivo

$J V O R$, n. registro

$\mathrm{VI}-430 \mathrm{~b}$ 
En fotografías de la época se puede reconocer claramente, que los cuadros tenían un diseño figurativo, entre ellos en forma de estrella." El parque se caracterizaba por sus anchos caminos. En 1892 fue descrito como "un jardín de severo estilo inglés"12 y en 1894 se aseguraba que "el (...) parque tiene bellísimos árboles, dos pilas de bronce, varios asientos de madera y está rodeado de una hermosa veria de hierro". ${ }^{3}$ Poco después de la Plaza Bolívar fueron convertidas otras antiguas plazas coloniales en parques y jardines públicos, entre ellas se encontraban la Plaza Santander y la Plaza de los Mártires, entre otras (localización ver 1). Los trabajos para la conversión en parque de la Plaza Santander se empezaron en 1881 bajo la dirección de Casiano Salcedo. ${ }^{14}$ A diferencia de la plaza de Bolívar, se utilizó en el Parque Santander toda el área para la realización del parque. El centro del parque fue ocupado por un monumento a Francisco de Paula Santander (1792-1840), una de las figuras mas importantes de la Independencia de Colombia (Figura 5). Según una descripción de 1894 el parque estaba dividido en dos mitades, que incluían varios cuadros y grupos de árboles. Además existían dos fuentes de bronce y algunos bancos de madera. El parque estaba encerrado por una reja de hierro y tenía entradas por el lado oriental y occidental. ${ }^{15} \mathrm{El}$ parque se convirtió en el sitio de esparcimiento más importante de la ciudad, en el que desde 1883 tuvieron lugar serenatas los jueves y domingos. ${ }^{16}$

En 1883 fue construido el Parque Centenario, a raíz de la conmemoración del primer centenario del nacimiento de Simón Bolívar. Este fue el primer parque de la ciudad concebido como tal, y no del resultado de la transformación de una antigua plaza colonial. Para la construcción del parque, que sería destruido en 1957, se destinó un terreno localizado, en ese entonces, en el extremo norte de la ciudad (localización ver Figura 1). Se trataba de un terreno rectangular, cuyo diseño se caracterizaba por su simetría y por un eje que lo atravesaba en dirección oriente-occidente. En la mitad del parque se erigió un templete de piedra diseñado por el arquitecto italiano Pietro Cantini (1847-1929), destinado a alojar una estatua de Bolívar (Figura 6)..$^{17} \mathrm{El}$ templete estaba decorado con varios símbolos patrióticos, entre otros se encontraban en la parte

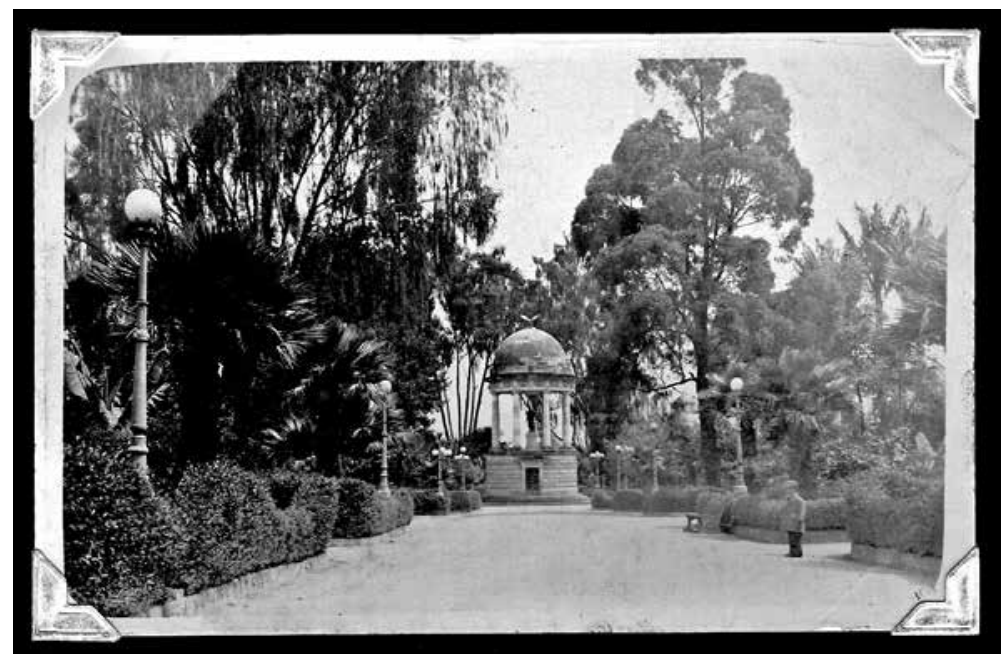

Figura 6: Parque Centenario con Templete Fuente: $S M O B$, Archivo $J V O R$, n. registro XVI$1269 \mathrm{c}$ 
interior de la cúpula escudos de las naciones bolivarianas y coronas de laurel. El parque contaba también con dos pilas de bronce, así como con un lago artificial, con el que se realizó probablemente una fuente en $1885^{18}$ Figura 7. En el mismo año se construyó un carrusel infantil, el primero de la ciudad. ${ }^{19}$ En 1896 el Parque Centenario era descrito como, "(...) el más grande en extensión, el más bello, el mejor oxigenado por sus aires puros, el preferido por la elegante sociedad para un paseo (...)". ${ }^{20}$

Las descripciones anteriores ejemplifican el diseño de los parques y jardines públicos realizados: ellos contaban con un monumento a uno de los héroes de la Independencia o relativo a las Guerras de la Independencia, como el Monumento a los Mártires (Figura 8), localizado en el Parque de los Mártires. La estatua o monumento se encontraba localizado centralmente y estaba rodeado por un jardín o parque, diseñado geométricamente, y protegido por una reja, que en la mayoría de los casos, había sido elaborada en Europa. Sobre la vegetación empleada existen informes detallados, entre ellos uno de 1896, redactado por el administrador de parques y jardines públicos, en el que el describe los árboles, arbustos y plantas de flores utilizados. Sobre la Plaza Bolívar nombra p.ej.: "Existen nueve pinos grandes, diez pequeños, dos araucarias, cuatro quinos, tres matas de plátanos, dos sietecueros, dos amarra-bollos y tres pinos" y sobre el Parque Santander "Plantas: 8 eucaliptus; (...), 4 sietecueros, una aralia, (...) y varios pinos". ${ }^{21}$ Se emplearon pues en su mayoría especies autóctonas, sin embargo, también se utilizaron algunas importadas, como el eucalyptus globulus, traído de Australia ${ }^{22}$ o araucarias chilenas (Figuras 9 y 10). Con respecto a la elección de plantas autóctonas - importadas afirmaba uno de los administradores de parques y jardines públicos, Genaro Valderrama, en 1889: "Debo advertir que habiendo en el país en la zona fría, gran número de variedades de árboles muchos mas bellos que los europeos, que en lo
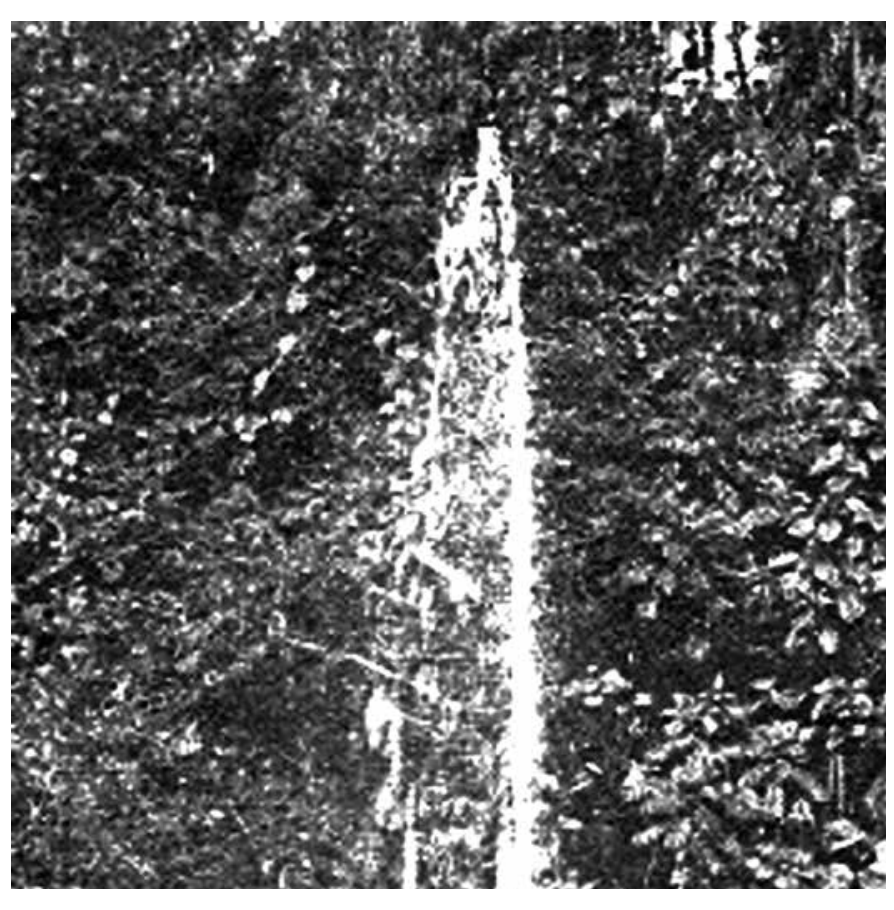

Figura 7: Parque

Centenario,

lago artificial

Fuente: SMOB, Archivo $J V O R, n$. registro $X V I-$

$1267 b$ 
general presentan un aspecto lúgubre y desapacible, yo me ocupare de emplear aquellos mesclados (sic) con estos, lo que así, podrán producir un efecto sobre manera agradable que no tienen los parques europeos." ${ }^{23}$ La elección de las plantas utilizadas se debió a motivos prácticos, es decir porque una especie en especial se tenía como adecuada, así como también por motivos estéticos o del diseño, no por motivos patrióticos. Un tema importante y discutido en el momento fue también la realización de un jardín botánico, que sin embargo no llegaría a ser realizado.

La función principal de estos parques y jardines públicos erigidos en la ciudad era representativa, es decir ellos debían salvaguardar los monumentos de los héroes de las Guerras de Independencia y los símbolos de la patria. Estos parques y jardines se orientaban en su diseño en prototipos europeos, como será demostrado posteriormente. La orientación hacia prototipos de Europa era de una manera decidida y consciente y se puede aclarar con la autoconciencia de los colombianos después de la terminación del régimen colonial. Por un lado el país buscaba una identidad propia, por el otro quería ser tomado como un país avanzado y civilizado. Ser civilizado fue visto como necesario para el deseado progreso del país. Sin embargo el concepto de civilización

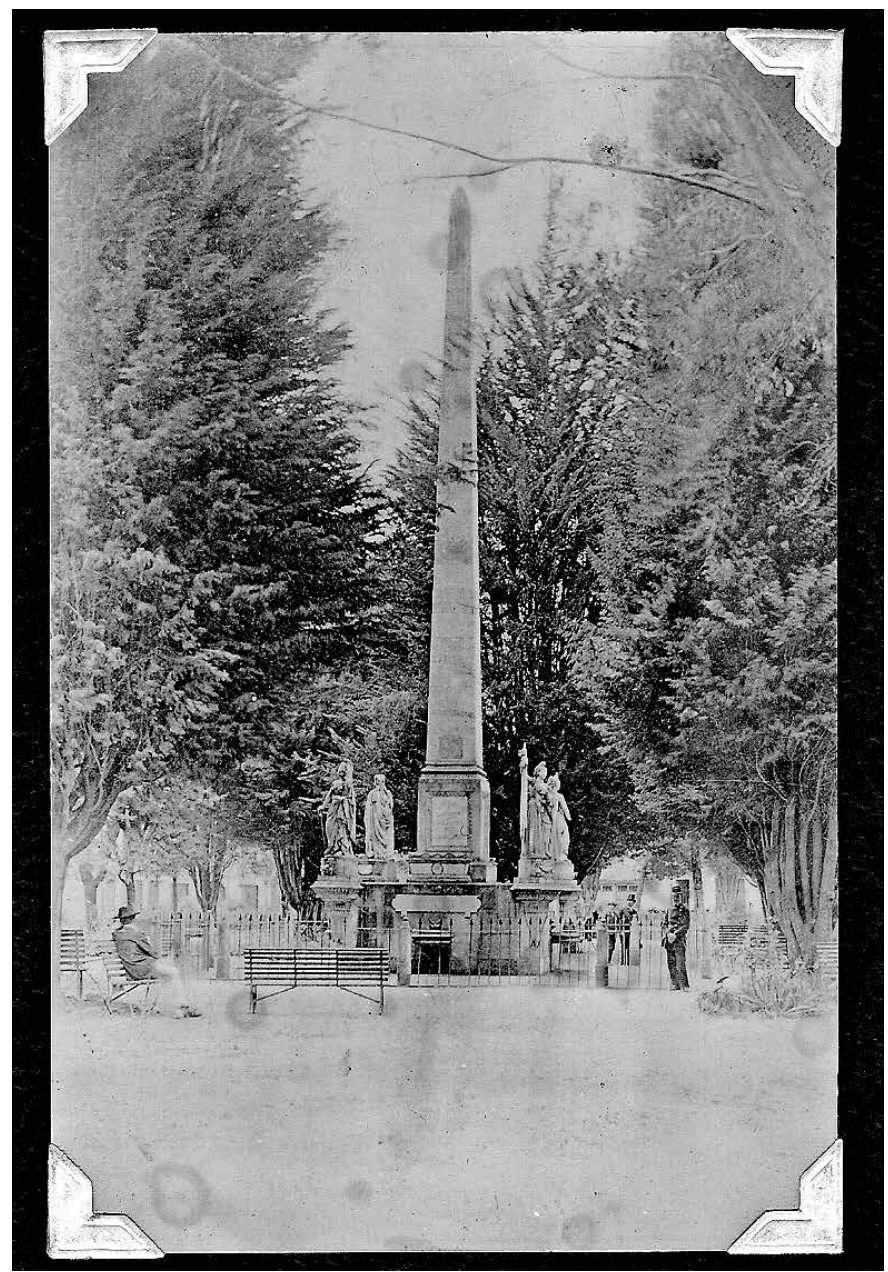

Figura 8: Parque de los Mártires, Monumento a los Mártires Fuente: $S M O B$, Archivo $J V O R$, n. registro IV-258a 


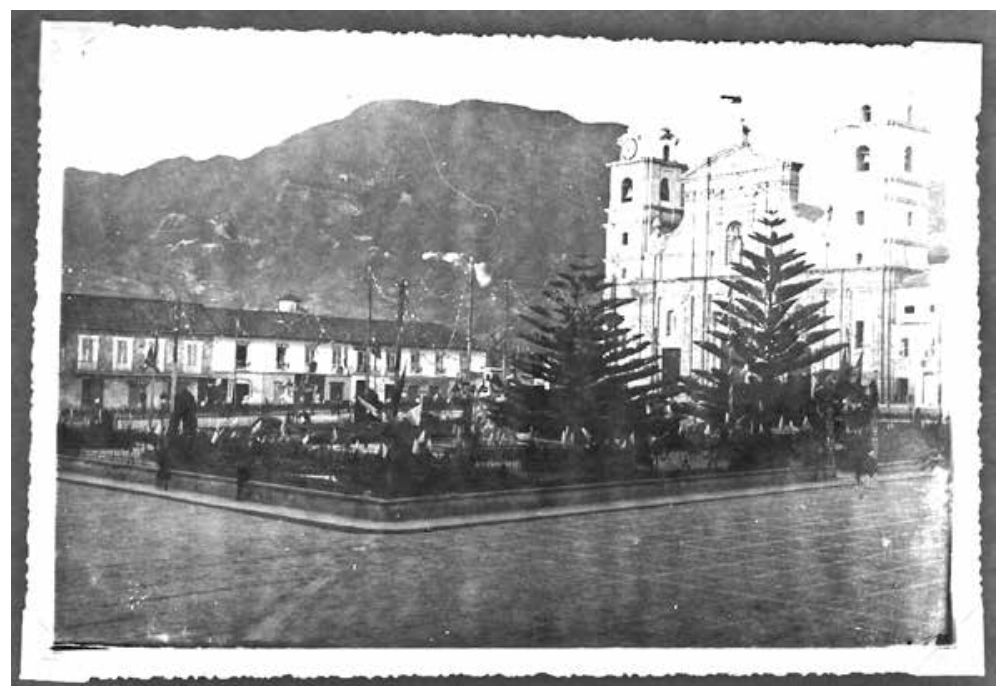

Figura 9: Plaza de Bolivar, Araucarias Fuente: SMOB, Archivo $J V O R$, n. registro $X V I-$ $1262 a$

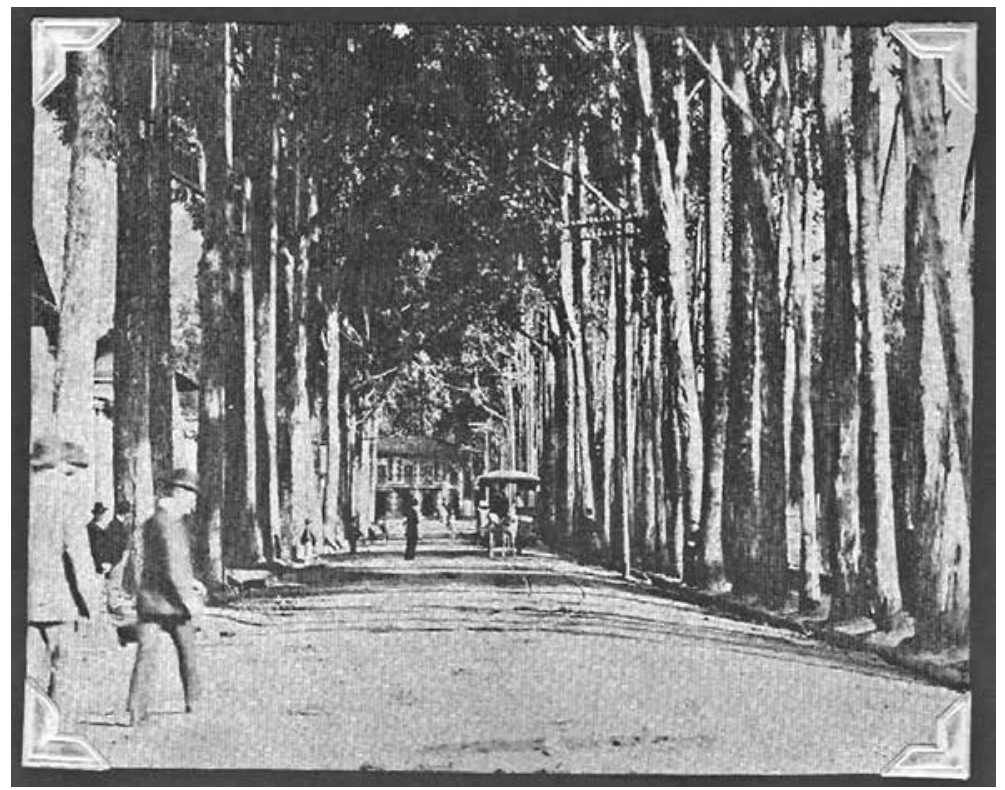

Figura 10: Parque

Centenario, eukalyptus globulus

Fuente: $\mathrm{SMOB}$, Archivo $J V O R$, n. registro $X V I-$ $1308 b$

era ambivalente: Las guerras de la Independencia habían liberado al país del régimen colonial, que había sido implantado bajo las premisas de la civilización. El futuro y el deseo de ser civilizado implicaban de todas maneras un encuentro con esa cultura europea y representaban de esta manera un dilema. Este no podía ser resuelto con el rechazo de la cultura europea, sino con la creación de un sentimiento igualitario y distanciado hacia los europeos. Se trataba de una doble misión para la cual los criollos, se sentían predestinados. ${ }^{24}$ Después de que el poder español ya no estaba presente los criollos intentaban identificarse con la civilización europea abiertamente. La ciudad y sobre todo Bogotá, debería convertirse en el escenario de la civilización por excelencia. ${ }^{25} \mathrm{El}$ progreso también fue asociado con el cuidado de la lengua española, las buenas maneras y el concepto de urbanidad, todas cualidades que hacían de Bogotá 
la "Atenas suramericana", ${ }^{26}$ una ciudad civilizada y culta. La supuesta falta de higiene y urbanidad, la existencia de algunas costumbres, entre ellas el consumo de chicha, ${ }^{27}$ ponían en peligro, ante los ojos de la clase alta, el progreso.

Los parques y jardines públicos de Bogotá eran comparables en su diseño, tamaño y composición con los squares parisinos, diseñados durante las medidas urbanísticas realizadas de 1853 a 1869 durante la reestructuración de París hecha bajo Georges-Eugène Baron Haussmann (1809-1891). El diseño de la Plaza Bolívar era similar al del Square Montholon o el Square des Innocents en París. El trazado del Parque Centenario era comparable con el Square Batignolles, el cual también estaba dividido por un eje. ${ }^{28}$

A finales del siglo XIX existía, paralelamente a la creación de los parques y jardines públicos nombrados anteriormente, una discusión sobre el arte de la jardinería, así como la exigencia de que se crearan otro tipo de parques, que no solamente tuvieran una función representativa, sino que también ofrecieran una solución a los problemas de la ciudad.

La jardinería pública era manejada y administrada por el Ministerio de Fomento, quien encargaba a contratistas, administradores y jardineros "para que los [Los parques y jardines públicos] cultive, vigile y mejore el buen estado en que se le entregan (...) el se obliga a mantener en dichos parques un plantío firmemente y variado de plantas floríferas, arbustos y árboles colocados con arte y simetría (...)"29. Los contratistas y administradores podían pues decidir sobre el diseño, también "(...) puede introducir libremente en los jardines de cultivo de las clases de flores que crea mas convenientes para su ornato", pero "para hacer modificaciones sustanciales respecto de arbustos o árboles o con relación a la forma general de cada parque o jardín, necesita la aprobación previa del gobierno"30. Es decir ellos tenían cierta libertad, pero las decisiones importantes sobre el aspecto general eran tomadas por el Gobierno directamente, lo que significa que al arte de la jardinería se le atribuía una gran importancia y relevancia. Esto lo demuestra también el hecho de que, "La mejora y conservación de los parques y jardines públicos de Bogotá debe ponerse al cuidado de persona entendida y práctica en la materia, si se quiere que el servicio dé resultados satisfactorios", ${ }^{31}$ como se afirmaba en un acta del ministerio.

El arte de la jardinería pública estaba en manos de jardineros y botánicos. Las figuras más importantes por la cantidad de proyectos planeados o por sus afirmaciones, fueron Genaro Valderrama y Casiano Salcedo. Ambos fueron administradores de los parques y jardines públicos por varios años. Salcedo fue responsable del diseño de varios parques, entre ellos en las Plazas Bolívar, Santander y los Mártires ${ }^{32}$ y se definía a si mismo como autodidacta de la botánica. Ellos y otras personas que se ocupaban con el arte de la jardinería en Bogotá tenían conocimiento sobre botánica y sobre la jardinería, y conocían proyectos paisaíisticos europeos, como los proyectos parisinos bajo Alphand, por viajes o por medio de literatura, como aparece en numerosas citas de la época. También trabajaron algunos jardineros extranjeros en Bogotá, entre los que están el alemán Wilhelm Kalbreyer. ${ }^{33}$ Estas personas que trabajaban en el arte de la jardinería en Bogotá tenían contacto con paisajistas y horticultores extranjeros, entre ellos con Louis Van Houtte en Gent, y con la Casa Vilmorin en Paris ${ }^{34}$ para la conse- 
cución de semillas e intercambio de plantas. También estuvieron en Colombia en el siglo XIX algunos botánicos y paisajistas extranjeros, cuya presencia tuvo que ver con la búsqueda y recolección de flores para los jardines europeos, sobre todo de orquídeas. ${ }^{35}$ A finales del siglo XIX estuvieron en Bogotá dos paisajistas europeos. Uno de ellos fue Edouard André (1840-1911), quien seria enviado en 1875 por el gobierno francés a una expedición al norte de los Andes suramericanos, que incluía al territorio colombiano. En su informe de viaje, que fue publicado entre 1877 y 1883 en varios artículos de la revista Le Tour du Monde, describe André varios aspectos del país. Ahí también aparece publicado el plano de un „jardín en Bogotá", del cual se trata probablemente del jardín privado de una casa. ${ }^{36}$ La presencia de André parece haber tenido que ver solamente con la consecución de plantas para la exportación, ya que no existe vestigio de ningún proyecto para Bogotá. En 1893 estuvo el británico Robert Thomson en Bogotá, quien había trabajado anteriormente de 1867 a 1877 como superintendent de los jardines públicos y del jardín botánico en Jamaica. ${ }^{37}$ Thomson parece haber sido invitado por el Gobierno Colombiano para proponer la climatización de algunas plantas en el país, como el caucho y la pimienta negra, pero también para asumir el cargo de superintendent de los parques y jardines públicos de Bogotá, el cual no llegaría a ejercer. ${ }^{38}$

La discusión sobre el arte de la jardinería se concentraba en la crítica del diseño, la apariencia y la función de los parques existentes, así como en la exigencia de la creación de nuevos parques. Los principales protagonistas de esta discusión son los anteriormente nombrados Thomson y Valderrama. Thomson se refería en varias cartas a los parques existentes, como fuera en una carta de enero de 1893 en la que afirmaba: "En todos los parques públicos, (...) de Bolívar, de Santander, del Centenario y de Los Mártires, se ha cometido un gran error en su formación: me refiero a los paseos limitados inmediatamente por las verjas de hierro, pues en vez de éstas han debido establecerse arbustos pequeños para no dejar un paseo a orillas de una calle. Del punto de vista de la jardinería estos espacios ocupados por paseos, además de ser objetables, dan por resultado una gran extensión de espacio perdido que llega algunas veces a ser de 16 a 20 pies de ancho en contorno de la verja. ${ }^{\prime 39}$ En la misma carta agregaba sobre el Parque Centenario: "Las filas de eucalyptus, tanto adentro como fuera de la veria, forman al presente la parte más importante de este parque: pocos años más y ellos lo harán invisibles. El eucaliptos alcanza proporciones gigantescas y sus anchurosas ramas, junto con sus raíces que se extienden extraordinariamente son perjudiciales a casi todas las especies de plantas que le queden inmediatas."

Valderrama criticaba por un lado el aspecto de los parques existentes de la siguiente manera en 1895: "lo que aquí llamamos con el nombre pomposo de parques, no lo son ni pueden serlo por lo reducido del espacio de esas plazas en donde, solo existen una montonera de árboles colocados sin gusto, sin arte y sin reglas ningunas de jardinería." ${ }^{\prime 1}$ Poco después, en 1899, explicaba al respecto "Por parque se entienden extensiones de terreno mayores de tres hectáreas, en donde se procuran imitar los paisajes mas bellos de la naturaleza como bosques, rocas, prados, cascadas, lagos, para lo cual se acaba de adornar con pagodas, belvederes, kioskos, ruinas, casas rústicas y otras clases de 
obras de arte que contribuyen a producir efectos sobremanera agradables (...) un jardín se compone solo de plantas de flores colocadas de manera de ofrecer a la vista combinaciones en que resalta el lujo suntuoso de esa clase de vegetación, y que produzca placenteras emociones" y agregaba sobre los parques de Bogotá "(...) con las flores se hacen en el extranjero jardines admirables, que entusiasman (...) por su aspecto pintoresco, mientras que aquí todo es monótono y desapacible". ${ }^{42}$ Según Valderrama no era posible crear un parque en las plazas bogotanas, puesto que "(...) nuestras plazas no se prestan absolutamente para establecer en ellas por su reducido espacio, necesitándose para tal fin grandes extensiones de terreno en donde se puedan desarrollar las vistas pintorescas que ellos requieren procurando imitar los paisajes mas bellos de la naturaleza". ${ }^{43}$

Por otro lado Valderrama conocía la función que los parques podían llegar a tener para contribuir a la mejora de las condiciones higiénicas, por eso resaltaba en una carta de 1897 "Está comprobado científicamente que la naturaleza ha encargado a la vegetación el absorber por sus hojas los gases deletéreos que circulan en la atmósfera (...) y convertirlos en oxigeno que tan necesario es para la conservación de la vida del hombre y de los animales (...) " 44 y refiriéndose concretamente a Bogotá agregaba en la misma carta "Aquí se ha creído que con mantener aseadas las calles y algunas casas, esto basta para mantener la salubridad en la ciudad (...) Por consecuencia pues una vez que se sabe que la vegetación es el agente más poderoso que obre sobre la salubridad pública, deben hacerse todos los esfuerzos posibles para aumentar la vegetación en la ciudad, pues la que hay en los parques y jardines públicos y privados no es suficiente para una población como la de esta capital". ${ }^{45}$ Es seguro por esta razón que Valderrama ya había propuesto en 1889: "Además, si como se ha pensado, se quiere llevar a efecto la formación de un parque positivo en las inmediaciones de esta capital, yo me encargo de establecerlo tal como debe serlo, adoptando un plano por el estilo del que presento con las modificaciones necesarias para semejarlo al de Monceau en Paris, que es el mas bello que conozco." ${ }^{166}$ En 1896 se seguía hablando de la necesidad de un nuevo parque, de la siguiente manera "En todas las capitales civilizadas del mundo hay un centro que atrae en los días de descanso a las gentes, en donde encuentran diversiones honestas y apropiadas para ellas y sus familias, que aleja de ciertos focos de corrupción especialmente a la juventud, tales como el Central Park en New York, el High Park (sic) en Londres y el Bois de Boulogne en París. La mayor parte de los habitantes de estas felices poblaciones se trasladan allí en busca de expansión y alegría, y vuelven, al empezar la semana al trabajo o al estudio, sin que un pesar les acompañe. Nuestra capital, ya un poco populosa, necesita de un canto y de algo que aleje a nuestra juventud de los clubs o casinos". ${ }^{47}$ Se nota pues que se solicitaba un parque apropiado para satisfacer las necesidades higiénicas y sociales de la ciudad, el cual al parecer ya estaba en planeación.

Este artículo muestra la práctica y la teoría de la jardinería en Bogotá en una nueva luz. Es cierto que en Bogotá a finales del siglo XIX, comparativamente con otras ciudades latinoamericanas, la presencia de paisajistas europeos fue muy reducida. En países como Argentina, Chile y Uruguay había sido de gran importancia la presencia desde los años 1820 de paisajistas y botánicos franceses, entre ellos Aimé Bonpland, Char- 
les Thays, Eugéne Courtois y Edouard André, quienes habían desarrollado numerosos proyectos, algunos de los cuales llegarían a realizarse. ${ }^{48}$ También es cierto que fueron pocos los proyectos realizados en Bogotá, de los cuales se trataba principalmente de antiguas plazas coloniales convertidas en parques y jardines públicos representativos. Sin embargo este artículo demuestra que en Bogotá si existían desde finales del siglo XIX muchas personas que se dedicaban al arte paisajístico, también había un intento de una teoría, un conocimiento de teorías y parques extranjeros, así como un intercambio con paisajistas y botánicos extranjeros. Además también se reconocía y se discutía la necesidad de un nuevo tipo de parque, un aspecto importante de resaltar, aunque el deseado "parque extenso y amplio para dotar con él a nuestra querida capital" no hubiera sido construido en esos momentos.

\section{Notas}

(1) ARCHIVO GENERAL DE LA NACIÓN (A CONTINUACIÓN: AGN). Sección República, Bogotá Aseo: Fondo Ministerio de Obras Públicas (MOP), tomo 860, folio 131.

(2) Akademie der Wissenschaften der Ddr und Kolumbianische Akademie der Wissenschaften (Ed). Alexander von Humboldt in Kolumbien - Auswahl aus seinen Tagebüchern. Bogotá: Flota Mercante Grancolombiana, 1982, p. 43. Cita original: "Stadt höchstens 30000 Einwohner - liegt am Abhange einer Bergkette, während man in der ganzen Ebene eine bessere Lage suchen könnte. (...) Es ist überhaupt ein sonderbares Unternehmen, (...) Gebirgskuppe in einer Höhe, welche den Rükken der Pyrenäen übertrifft, sich anzusiedeln (...)."

(3) Santafé de Bogotá fue fundada al pie de la cordillera de los Andes por Gonzalo Jiménez de Quesada el 6 de agosto de 1538, en un territorio habitado anteriormente por los chibchas Esta fecha se ha establecido como la fecha oficial de la fundación de la ciudad, a pesar de que no existe más el acta oficial, ver, entre otros IRIARTE, Alfredo. Breve historia de Bogotá. Bogotá: Editorial Oveja Negra, 1988, p. 21 y ESCOVAR, Alberto; MARIÑO, Margarita; PEÑA, César. Atlas histórico de Bogotá 1538-1910. Bogotá: Editorial Planeta, Corporación la Candelaria y Alcaldía Mayor de Bogota, 2004, p. 22.

(4) En la literatura existen varias teorías sobre la aparición, utilización y expansión del damero en Latinoamérica, ver p. ej.: HOFER, Andreas. Karl H. Brunner und die Rolle des europäischen Städtebaus in Lateinamerika, 2000, 273 p. Tesis (Doctorado) - Fak. für Raumplanung und Architektur Technische Universität Wien. Wien, 2000, p. 13. El trazado de Bogotá ha sido denominado en la literatura como una variación del trazado de Santo Domingo en la República Dominicana, realizado en 1502, ver: MARTINEZ, Carlos. Bogotá - sinopsis sobre su evolución urbana. Bogotá: Escala Fondo Ed., 1976, p. 26. Las Leyes de Indias, promulgadas en 1573 por el Rey Felipe II, se refieren explícitamente a los procesos de urbanización en las colonias americanas. En estas fueron reguladas la forma y la estructura de las ciudades, también lo referente a la localización de los diferentes edificios, etc., ver: LEJEUNE, Jean-François. "Dreams of order: utopie, cruelty and modernity." En: Cruelty \& utopia - cities and landscapes of Latin America, first published in connection with an exhibition at the CIVA in Brussels, may-out. New York, 2003, p. 31-49.

(5) MEJIA PAVONY, Germán Rodrigo. Los años del cambio - historia urbana de Bogotá 1820-1910. Bogotá: Centro Editorial Javeriano Ceja, 2. ed., 2000, p. 230. En 1801 Bogotá contaba con 21.394 habitantes y en 1912 con 116.951.

(6) MEJIA PAVONY, 2000, p. 417.

(7) Con el Acuerdo del 20.7.1845 se renombró la Plaza Mayor en Plaza de Bolívar, ver: MARTINEZ 1976, p. 120. La historia de la Plaza Bolívar y del monumento a Bolívar están bien documentadas, ver, entre otros: ESCOVAR, 2004, p. 230-231 y MARTINEZ, 1976. Simón Bolívar (1783-1830), Libertador de Colombia, Venezuela, Panamá, Ecuador, Perú y Bolivia, es una de las figuras más importante de las guerras de la Independencia en Suramérica.

(8) Casiano Salcedo fue una de las figuras más importantes en el arte de la jardinería pública de Bogotá a finales del siglo XIX, para una reseña sobre su vida, ver: ORTIZ WILLIAMSON, G., Casiano Salcedo. Bogotá: Cromos, v. I, n. 106, p. 138-139, 1918.

(9) A finales del siglo XIX no existió en Bogotá un consenso general sobre la tipología de los parques y jardines, es decir no había una definición exacta sobre lo que era un parque, jardín o plaza. En el año 1894 se denominan plaza-parque al Bolívar, Santander y Centenario, mientras que los otros son llamados simplemente plazas, ver: PALAU, Lisímaco. Guía histórica y descriptiva de la ciudad de Bogotá. Bogotá: Imprenta de Vapor de Zalamea, 1894 , p. 30-31. Borda las denomina en su libro de 1886 como plazas, ver: BORDA, Ignacio. Almanaque para 
"Un Parque Extenso y Amplio para Dotar con él a nuestra Querida Capital": La Exigencia de la Creación de un Parque y el Panorama del Arte Paisajístico a Finales del Siglo XIX en Bogotá

todos y directorio completo de la ciudad con 12 vistas de Bogota para 1886. Bogotá: Facs., 1886. El administrador de los parques públicos de Bogotá, Genaro Valderrama, es el único que en ese momento intenta una definición en una carta del 8.10.1899, ver: AGN, MOP. Bogotá parques y jardines varios 1887-1916, tomo 823, folio 93.

(10) En la misma referencia, folio 25, informe sobre los trabajos realizados en los parques y jardines públicos de junio de 1892 por Casiano Salcedo.

(1 1) En 1892 Casiano Salcedo informó en este sentido haber saneado tres cuadros en forma de estrella, ver: AGN, tomo 823, folio 25.

(12) BORDA, Ignacio. Monumentos patrióticos de Bogotá - su historia y descripción, Bogotá, 1892, p. 11.

(13) PALAU, 1894, p. 31

(14) Palau afirma que los trabajos del parque fueron empezados en 1881, 1894, s. 31 . Borda, por el contrario dice que fueron empezados en febrero de 1880 por Salcedo, ver: BORDA, 1886, p. 209.

(15) PALAU, 1894, p. 31

(16) ORTEGA RICAURTE, Daniel. Historia del parque de Santander, Bogotá, 1926, p. 38.

(17) El templete fue inaugurado solo hasta el 20 de julio de 1884, ver: CANTINI ARDILA, Jorge Ernesto. Pietro Cantini - semblanza de un arquitecto. Bogotá: Corporación La Candelaria, 1990, p. 266. El centro del templete permaneció vacío hasta 1926, año en el cual fue erigida allí una réplica de la estatua de la Plaza de Bolívar, en: CORTAZAR, Roberto. Monumentos, estatuas, bustos, medallones y placas conmemorativas existentes en Bogotá. Bogotá, 1938, p. 49.

(18) En una fotografía histórica del Archivo de la Sociedad de Mejoras y Ornato se nombra una fuente, realizada en 1885, ver fotografía XVI 1267-b.

(19) PALAU, 1894, p. 32.

(20) AGN, Sección República, Fondo Ministerio de Obras Públicas. Bogotá Parques, Plazas y Jardines A.C. (18881905), tomo 828, folio 432-433, carta de Eufemio Moreno al ministro de Fomento, 20 mar. 1896.

(21) AGN, tomo 823, folios 307 y 309, Acta de entrega de los parques y jardines públicos al contratista Bernardo Tavera, 1 ago. 1896.

(22) Casiano Salcedo expresó en un artículo de 1918 haber introducido el eucalyptus globulus en la ciudad, ver: ORTIZ WILLIAMSON, G., Casiano Salcedo. Bogotá: Cromos, v. I, n. 106, p. 138-139, 1918.

(23) AGN, tomo 823, folio 5, carta de Genaro Valderrama al ministro de Fomento Braulio Vélez, 16 abr. 1889.

(24) ROJAS, Cristina. Civilización y Violencia - la búsqueda de la identidad en la Colombia del Siglo XIX. Bogotá: Grupo Editorial Norma, 2002, p. 66.

(25) En otras ciudades del país también se convirtieron plazas coloniales en jardines y parques, o se construyeron parques con carácter representativo, entre ellos el Bosque de la República en Tunja en 1918, la plaza y parque de la Pola en Riosucio (Caldas), el Parque la Libertad en Pereira, la Plaza de García Rovira, Parque Romero y el Parque de Santander en Bucaramanga.

(26) A varias personas se les ha atribuido ser las primeras en haber dado este nombre a la ciudad, como son Alexander von Humboldt o el viajero francés Pierre d'Espagnat, quien estuvo en Bogotá en 1898, ver: ALJURE, Luis Carlos; RUIZ, Claudia Angélica. En: http://209.85.129.132/search?q=cache:WkXGecYNkaOJ:www.revistadiners.com.co/noticia.php3\%3Fnt\%3D5460+atenas + suramericana +jorge + orlando + melo\&cd $=5 \&$ hl $=$ es\&ct $=$ clnk (consultado 1.9.1910). Según Zambrano fue el español Marcelino Menéndez Pelayo (1856-1912) el primero en comparar Bogotá con la capital griega, ver: ZAMBRANO PANTOJA, Fabio. "De la Atenas suramericana a la Bogotá moderna. La construcción de la cultura ciudadana en Bogotá. En: http://redalyc.vaemex.mx/ redalyc/src/inicio/ArtPdfRed.jsp?iCve.=81501102. Consultado 1 set. 1910.

(27) La chicha es una bebida alcohólica de maíz, de origen indígena.

(28) ver: ALPHAND, Adolphe. Les promenades de Paris. Reimpresión de la Edición de Paris, 1867-1873. Pennsylvania: Princeton Architectural Press, 1984.

(29) AGN, tomo 823, folio 57-59, contrato entre el Ministerio de Fomento y el contratista Agustín Torres Rojas, 3 mar. 1894.

(30) AGN, tomo 823, folio 282, contrato entre el Ministerio de Fomento y Casiano Salcedo, 30 jun. 1896.

(31) AGN, tomo 823, folio 352.

(32) ORTIZ WILLIAMSON, 1918, p. 139

(33) ORTIZ WILLIAMSON, 1918, p. 138. Wilhelm o Guillermo Kalbreyer (1847-1912) era un jardinero alemán, quien inauguró la primero floristería de Bogotá con el nombre "La Flora", ver: ESCOVAR, 2004, p. 461.

(34) ORTIZ WILLIAMSON, 1918, p. 138

(35) Las orquídeas suramericanas eran muy apetecidas en Europa por la época.

(36) POSADA, Eduardo. El viaje de Edouard André. En: ACEVEDO LATORRE, Eduardo (Ed.). Geografía pintoresca de Colombia - la Nueva Granada vista por dos viajeros franceses del siglo XIX Charles Saffray - Edouard André. Bogotá: Litogr. Arco, 2. ed., 1971, p. 67-180, p. 98. 
(37) Ver http://yourarchives.nationalarchives.gov.uk. Consultado 1 set. 2010.

(38) AGN, tomo 823, folio 32-37, carta de Robert Thomson al Ministro de Fomento, 30 jan. 1893.

(39) AGN, tomo 823, folio 32, carta de Robert Thomson al Ministro de Fomento, 30 jan. 1893.

(40) AGN, tomo 823, folio 32-37, carta de Robert Thomson al Ministro de Fomento, 30 jan. 1893.

(41) AGN, tomo 823, folio 66-67, carta del inspector de parques Genaro Valderrama al Ministro de Hacienda, 22 jul. 1895.

(42) AGN, tomo 823, folio 93. carta del inspector de parques Genaro Valderrama al director de Obras Públicas, 8 out. 1899.

(43) AGN, tomo 823, folio 99, carta del inspector de parques Genaro Valderrama al Ministro de Hacienda, 1897.

(44) AGN, tomo 823, folio 113, carta de Genaro Valderrama al Ministro de Hacienda, 4 abr. 1897.

(45) AGN, tomo 823, folio 114, carta de Genaro Valderrama al Ministro de Hacienda, 4 abr. 1897.

(46) AGN, tomo 823, folio 5, carta de Genaro Valderrama al Ministro de Fomento, 16 abr. 1889.

(47) AGN, MOP. Bogotá Parques, Plazas y Jardines A.C. 1888-1905, folio 432-433, carta de Eufemio Moreno al Ministerio de Fomento, 20 mar. 1896.

(48) Para ampliar este tema, ver: BERJMAN, Sonia. Plazas y parques de Buenos Aires: la obra de los paisajistas franceses 1860-1930. Buenos Aires: Fondo de Cultura Económica, 1998. 